Список литературы:

1. Утилизация батареек в России и мире URL: https://ria.ru/spravka/20131121/971073902.html [электронный ресурс]. Дата обращения 11.03.20017

2. Правильная утилизация батареек URL: https:/geektimes.ru/post/158299/ [электронный ресурс]. Дата обращения 15.03.20017

3. Как в России появился первый завод по переработке батареек URL: http://recyclemag.ru/article/kak-v-rossii-pojavilsja-pervyj-zavod-po-pererabotke-batareek [электронный ресурс]. Дата обращения 15.03.20017

4. Правильная утилизация батареек URL: http://vtorothodi.ru/pererabotka/pravilnayapererabotka-batareek [электронный ресурс]. Дата обращения 20.03.20017

\title{
Особенности экосистем в энергетической безопасности арктических энергозон Якутии
}

\author{
Мартынюк П.П., студент, \\ Технический институт (филиал) \\ Северо-Восточного федерального университета, г. Нерюнгри \\ E-mail: martynyuk.apollinariya@mail.ru
}

\section{Научный руководитель: к.т.н., доцент Киушкина В.P.}

Состояние энергетической безопасности говорит о состоянии экосистем, так как ее влияние прямо пропорционально влияет на экологическую безопасность окружающей среды. Как энергетическая безопасность влияет на состояние экосистем, так и экосистемы должны влиять на энергетическую безопасность. Россия слишком большая страна для того чтобы делать общие экологические требования к объектам энергетики на всей территории. Рекреационные возможности северных территорий малы, и темп обновления практически нулевой. Для соблюдения особенностей экосистем необходимо разработать специфичные экологические требования к объектам энергетики для каждой экосистемы отдельно, что позволит в значительной степени уменьшить губительное воздействие выбросов в различных климатических зонах.

Особенности экосистем в составе энергетической безопасности - это неповторимая биота с свойственной ей темпом микробиологического обновления в слиянии с объектами энергетики полностью соответствующими экологическим и энергетическим стандартам.

В мае 2014 года Президент Российской Федерации Владимир Путин подписал указ № 296, который определил сухопутные территории Арктической зоны России [1]. 


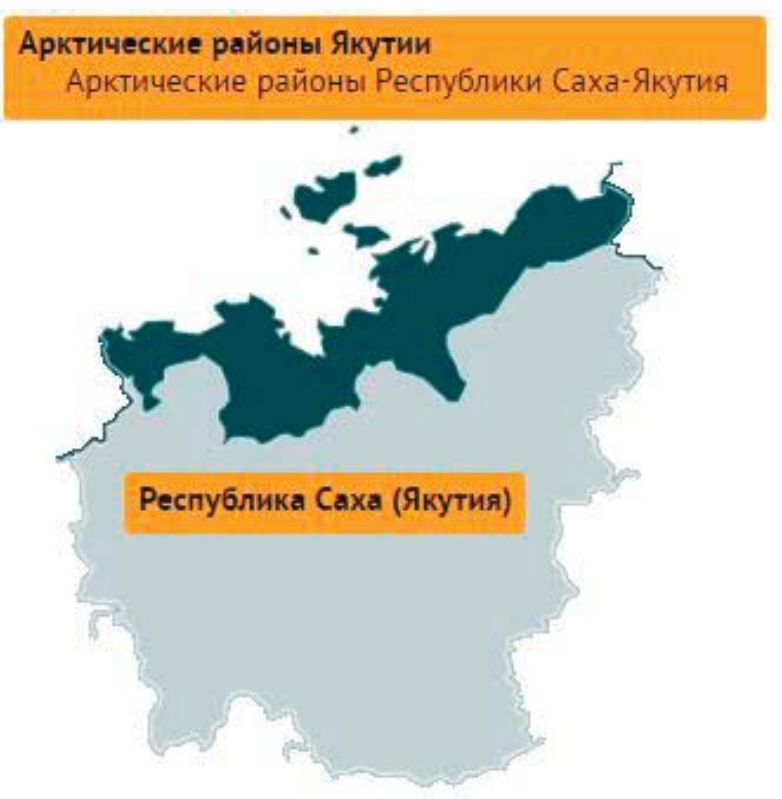

Рис. 1. Сухопутные территории Арктической зоны Республики Саха (Якутия) [1]

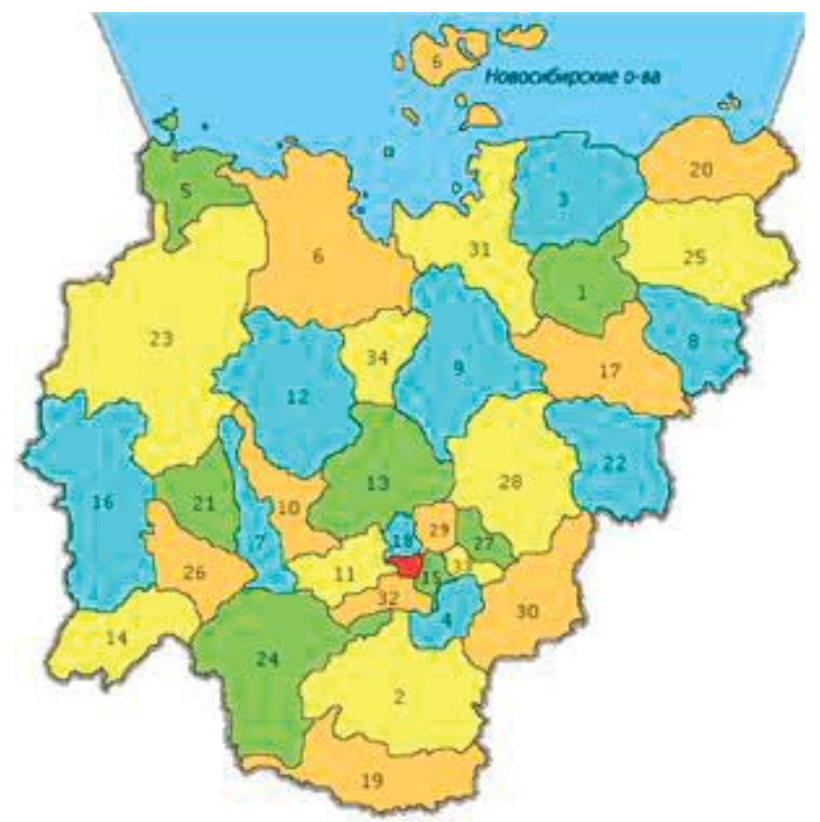

Рис. 2. Карта административного деления Республики Саха (Якутия) [2]

Республика Саха (Якутия) имеет на территории улусы, входящие в состав сухопутных территорий арктической зоны России:

5 - Анабарский национальный (долгано-эвенкийский) улус (район);

6 - Булунский район;

31 - Усть-Янский улус (район);

3 - Аллаиховский район;

20 - Нижнеколымский район.

Главной особенностью данных улусов является их экологическая значимость в экосистеме арктической зоны, так как на их территории располагаются заповедник и заказники.

Булунский район имеет на территории Усть-Ленский заповедник с уникальными легкоуязвимыми тундровыми биосообществами (около 400 видов растений, из них более 30 нуждающихся в защите, исключительное разнообразие рыб) [3].

Усть-Янский улус характерен тем, что в 2010 году на территории улуса был создан палеонтологический региональный государственный природный заказник Янские мамонты [4].

На территории Нижнеколымского района расположен заказник Плейстоценовый парк [5]. Заказник - охраняемая природная территория, на которой (в отличие от заповедников) под охраной находится не природный комплекс, а некоторые его части: только растения, только животные, либо их отдельные виды, либо отдельные историкомемориальные или геологические объекты [6].

Наличие охраняемых территорий позволяет сказать, что защита экосистемы от последствий энергетической деятельности является первостепенной задачей.

Природа арктических зон очень ранима. Загрязнение воздуха выбросами ДЭС, мини-ТЭЦ и котельными ТЭС является губительным для экосистемы. Тяжелые частицы отработанного топлива попадают на землю по истечении определенного времени, которое зависит от ветра и состава выбросов. Накопление вредных веществ от выбросов происходит из-за тонкого слоя плодородной почвы на вечной мерзлоте, 
который в свою очередь восстанавливается крайне медленно.

У почв арктических зон пониженный темп микробиологического обновления изза низких температур, следовательно, функции почвенных ресурсов минимизированы, значит, темпы очищения снижены. Низкие температуры замедляют процессы очищения, что характерно и для водных систем. Скорость накопления вредного вещества возрастает из-за замедленного очищения. На территории Якутии микробиологическая биота специфична (бедна видами микроорганизмов как в количественном плане, так и в качественном).

Для определения количественного расположения и процентного соотношения энергетических объектов на территории улусов составлена таблица 1.

Таблица 1

\begin{tabular}{|l|c|c|c|c|}
\hline \multirow{2}{*}{\multicolumn{1}{|c|}{ Улус }} & \multicolumn{4}{|c|}{ Энергетические объекты, используемые на данной } \\
\cline { 2 - 5 } & $\begin{array}{c}\text { территории } \\
\text { диельные } \\
\text { станции }\end{array}$ & $\begin{array}{c}\text { Мини- } \\
\text { ТЭЦ }\end{array}$ & ВЭС & $\begin{array}{c}\text { Котельные } \\
\text { ТЭС }\end{array}$ \\
\hline $\begin{array}{l}\text { Анабарский национальный (долгано- } \\
\text { эвенкийский) улус (район) }\end{array}$ & 2 & 1 & 1 & 0 \\
\hline Булунский район & 7 & 4 & 5 & 0 \\
\hline Усть-Янский улус (район) & 5 & 3 & 2 & 5 \\
\hline Аллаиховский район & 5 & 1 & 1 & 0 \\
\hline Нижнеколымский район & 5 & 0 & 1 & 0 \\
\hline Всего:48 & 24 & 9 & 10 & 5 \\
\hline Всего:100\% & $50 \%$ & $18,75 \%$ & $20,83 \%$ & $10,42 \%$ \\
\hline
\end{tabular}

Из таблицы выявлены по процентному соотношению энергетические объекты на территории арктической зоны РС (Я):

- ДЭС составляющие 50\%;

- ВИЭ (ветряные электростанции) составляющие 20,83\%;

- Мини-ТЭЦ составляющие 18,75\%;

- Котельные ТЭС составляющие $10,42 \%$.

Вышеприведенные данные позволяют сделать вывод, что ВЭС занимают не последнее место в обеспечении электроэнергией населения арктических районов Якутии. Ветряная энергетика соответствует всем условиям, необходимым для причисления ее к экологически чистым методам производства энергии. Ее основными преимуществами являются [7]: 1. Отсутствие загрязнения окружающей среды производство энергии из ветра не приводит к выбросам вредных веществ в атмосферу или образованию отходов; 2. Использование возобновляемого, неисчерпаемого источника энергии, экономия на топливе, на процессе его добычи и транспортировки; 3. Территория в непосредственной близости может быть полностью использована для сельскохозяйственных целей; 4. Стабильные расходы на единицу полученной энергии, а также рост экономической конкурентоспособности по сравнению с традиционными источниками энергии. Данное качество подтверждено таблицей 1; 5. Минимальные потери при передаче энергии - ветряная электростанция может быть построена как непосредственно у потребителя, так и в местах удаленных, которые в случае с традиционной энергетикой требуют специальных подключений к сети; 6. Простое обслуживание, быстрая установка, низкие затраты на техническое обслуживание и эксплуатацию.

Согласно «Энергетической стратегии России на период до 2030 года», 
утвержденной распоряжением Правительства РФ от 13 ноября 2009 г. N 1715-р, были ужесточены экологические требования к объектам энергетики. За годы её реализации был достигнут существенный прогресс в сфере повышения экологической безопасности энергетики. Основной целью государственной энергетической политики в сфере обеспечения экологической безопасности энергетики является последовательное ограничение нагрузки топливно-энергетического комплекса на окружающую среду и климат путем снижения выбросов (сбросов) загрязняющих веществ в окружающую среду, а также эмиссии парниковых газов, сокращение образования отходов производства и потребления.

В связи с этим наиболее выгодно с экологической точки зрения применять ветряные электростанции, которые позволяют устранить отрицательное воздействие на экосистему арктических улусов.

Подробнее рассмотрим состояние объектов энергетики на территориях с заказниками, т.к. они являются наиболее восприимчивыми к последствиям технологических благ. На территории Булунского района, Усть-Янского улуса и Нижнеколымского района расположено значительно большее количество ДЭС, чем других видов объектов промышленной энергетики.

Дизельная электростанция (дизель-генераторная установка, «дизель-генератор») стационарная или подвижная энергетическая установка, оборудованная одним или несколькими электрическими генераторами с приводом от дизельного двигателя внутреннего сгорания [8]. Из данного определения можно сделать вывод о том, что срок службы всего электроагрегата зависит от установленных на них различных по классу двигателей.

Установленная мощность дизельных электростанций по улусам имеет значительный диапазон, что усложняет технический контроль эксплуатации обслуживания установок. Индикативный показатель по степени износа ОПФ ДЭС улусов является статистическим значением, определяемым на основе данных ОАО АК «Якутскэнерго». Результаты данных представлены на рисунке 3 [9].
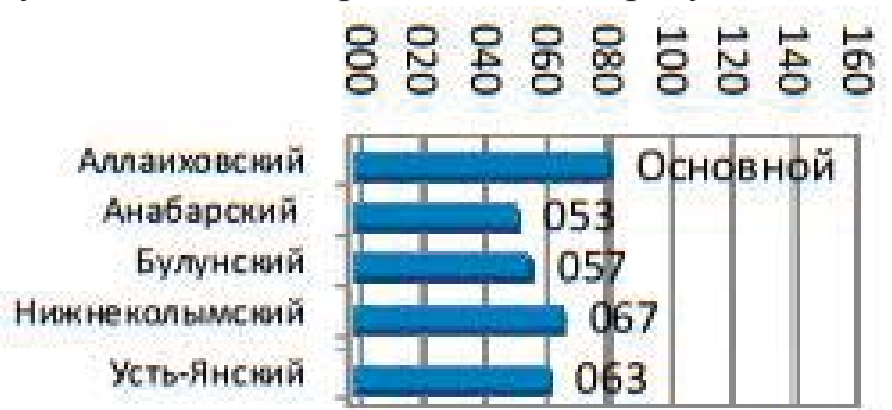

- Степень износа ДЭС

Рис. 3. Степень износа ДЭС улусов, \%

Высокий уровень данного показателя определяется недостатком инвестирования. При степени износа основных производственных фондов, превышающих 60\%, улусы будут относиться к такому уровню энергетической безопасности, как угрожающая стадия кризиса [7]. 


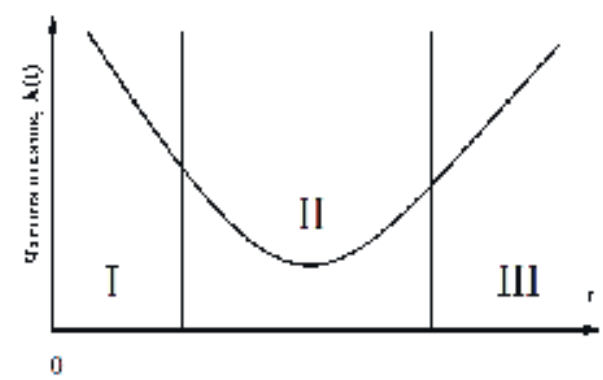

Рис. 4. Изменение интенсивности отказов при увеличении наработки объекта I - «выгорающие» отказы; II - случайные отказы; III - деградационные отказы

В нашем случае ДЭС находятся на стадии деградационных отказов, которые встречаются чаще всего на заключительной стадии эксплуатации объекта, когда вследствие естественных процессов старения и изнашивания объект или его элементы приближаются к предельному состоянию. Для снижения количества отказов предусматривается соответствующая система технического обслуживания и ремонта, но из рисунка 3 можно сделать вывод, что соответствующие мероприятия не проводятся из-за нехватки инвестиций.

Увеличение числа отказов способствует снижению безотказности электрооборудования. В свою очередь нарастает моральный и физический износ, что приводит всё к более вредным выбросам и дорогостоящим ремонтам. Для арктических зон целесообразно ужесточить соблюдение экологических норм, так как природа уникальна и более уязвима. Данное мероприятие позволит сохранить уникальные биосообщества.

\section{Список литературы:}

1. Арктические регионы URL: http://www.arctic-info.ru/regions/ режим доступа свободный [Электронный ресурс]. Дата обращения 27.02.2017

2. Административное деление $\mathrm{PC}(Я) \quad$ URL: https://ru.wikipedia.org/wiki/\%D0\%AF\%D0\%BA\%D1\%83\%D1\%82\%D0\%B8\%D1\%8F режим доступа свободный [Электронный ресурс]. Дата обращения 27.02.2017

3. Булунский район URL: https://ru.wikipedia.org/wiki/\%D0\%91\%D1\%83\%D0\%BB\%D1\%83\%D0\%BD\%D1\%81\%D 0\%BA\%D0\%B8\%D0\%B9_\%D1\%83\%D0\%BB\%D1\%83\%D1\%81 режим доступа свободный [Электронный ресурс]. Дата обращения 27.02.2017

4. Усть-Янский улус URL: https://ru.wikipedia.org/wiki/\%D0\%A3\%D1\%81\%D1\%82\%D1\%8C\%D0\%AF\%D0\%BD\%D1\%81\%D0\%BA\%D0\%B8\%D0\%B9_\%D1\%83\%D0\%BB\%D1\%83 \%D1\%81\#.D0.9E.D1.85.D1.80.D0.B0.D0.BD.D0.B0_.D0.BF.D1.80.D0.B8.D1.80.D0.BE.D 0.B4.D1.8B режим доступа свободный [Электронный ресурс]. Дата обращения $\underline{27.02 .2017}$

5. Нижнеколымский район URL: https://ru.wikipedia.org/wiki/\%D0\%9D\%D0\%B8\%D0\%B6\%D0\%BD\%D0\%B5\%D0\%BA\% D0\%BE\%D0\%BB\%D1\%8B\%D0\%BC\%D1\%81\%D0\%BA\%D0\%B8\%D0\%B9_\%D1\%80\% D0\%B0\%D0\%B9\%D0\%BE\%D0\%BD режим доступа свободный [Электронный ресурс]. Дата обращения 27.02.2017

6. Заказник URL: https://ru.wikipedia.org/wiki/\%D0\%97\%D0\%B0\%D0\%BA\%D0\%B0\%D0\%B7\%D0\%BD\% 
D0\%B8\%D0\%BA режим доступа свободный [Электронный ресурс]. Дата обращения $\underline{27.02 .2017}$

7. BЭC URL: https://alternativenergy.ru/vetroenergetika/581-plyusy-minusyvetroenergetiki.html режим доступа свободный [Электронный ресурс]. Дата обращения $\underline{27.02 .2017}$

8. ДЭС URL: http://naukovedenie.ru/PDF/38tvn113.pdf режим доступа свободный [Электронный ресурс]. Дата обращения 27.02.2017

Степень износа ДЭС URL: http://dic.academic.ru/dic.nsf/ruwiki/900155 режим доступа свободный [Электронный ресурс]. Дата обращения 27.02.2017

\section{Актуальность внедрения малых ГЭС с комбинацией СЭС в условиях Крайнего Севера}

Местников Н.П., слушатель, ГАУ ДПО «Высшая икола инновационного менеджмента при Главе РС (Я)», г. Якутск E-mail: nikolai.miestnikov.96@mail.ru

\section{Научный руководитель: к.г.н., профессор Константинов А.Ф.}

Одной из серьезных проблем функционирования энергосистемы Якутии является то, что обособленность энергорайонов не позволяет рационально использовать структуру энергетического хозяйства республики централизованного электрообеспечения, повысить надежность энергоснабжения и создать конкурентную среду по производству электроэнергии. [2] Функционирование энергетики Севера республики характеризуется сложной транспортной схемой доставки топлива с несколькими перевалками. Высокая стоимость топлива в местах потребления, низкие технико-экономические показатели существующих энергоисточников малой мощности приводят к высокой себестоимости производства электроэнергии и тепла (в России ежегодно на завоз топлива в северные регионы затрачивается более 16 млрд. руб., в том числе в северные районы РС(Я)- свыше 7 млрд. руб., а протяженность пути составляет 500-600 суток и износ ДЭС на 40\%-60\%, несмотря на то, что на территории РС (Я) за год введутся в эксплуатацию 7 новых ДЭС). [2]

\section{Основные методы повышения показателей мошностей энергетики РС(Я)}

В данное время решениями данной проблемы являются комбинированные электрические станции, такие как [1]:

1. ДЭС + МГЭС (при непостоянных расходах воды в реке ДЭС + СЭС + МГЭС);

2. ДЭС + ВЭУ + СЭС;

3. МГЭС + ВЭС;

4. ДЭС + БПГЭС и т.д.

СЭС выполняет роль вспомогательного источника электроэнергии, доля электроснабжения которой составляет от 10\% до 20\% в основных СЭС, которые имеется у АО «Сахаэнерго». Следует отметить, что северный энергорайон отличается тем, что период полярной ночи начинается с 5-7 декабря по середине февраля, согласно данным по Усть-Янскому району. Поэтому СЭС вырабатывает электроэнергию в 